\title{
Antiviral therapeutic approaches for human rhinovirus infections
}

\author{
Victor Casanova1 ${ }^{1}$ Filipa H Sousa ${ }^{1}$, Craig Stevens ${ }^{1}$ \& Peter G Barlow*,1 \\ ${ }^{1}$ School of Applied Sciences, Edinburgh Napier University, Edinburgh EH11 4BN, Scotland \\ *Author for correspondence: Tel.: +44 0131455 6167; p.barlow@napier.ac.uk
}

\begin{abstract}
Human rhinoviruses are the primary etiological agent of the common cold. This infection can be mild and self-limiting in immunocompetent hosts, but can be associated with bronchiolitis in infants, pneumonia in the immunosuppressed and exacerbations of pre-existing pulmonary conditions such as asthma or chronic obstructive pulmonary disease. Many of these conditions can place significant economic costs upon healthcare infrastructure. There is currently no licensed vaccine for rhinovirus, as the large variety of rhinovirus serotypes has posed significant challenges for research. In this review, we discuss current knowledge around antiviral drugs and small molecule inhibitors of rhinovirus infection, as well as antiviral host defense peptides as exciting prospects to approach the development of novel therapeutics which target human rhinovirus.
\end{abstract}

First draft submitted: 29 January 2018; Accepted for publication: 20 April 2018; Published online: 12 June 2018

Keywords: antiviral drugs $\bullet$ cathelicidin $\bullet$ interferon $\bullet$ peptide $\bullet$ rhinovirus $\bullet$ vitamin D

\section{Background}

\section{Human rhinoviruses}

Human rhinoviruses (RVs) are small $(27 \mathrm{~nm})$, nonenveloped, ssRNA viruses of the Picornaviridae family. More than 160 strains of RV have been identified and classified into three genetic clades (A, B and C) according to sequence similarity [1]. Competition assays for cellular binding sites have further grouped RVs into major group or minor group viruses depending on the use of ICAM-1 or LDLR as receptors [1]. Recently, the asthma susceptibility gene product, CDHR3, has been shown to mediate RV-C binding and replication [2].

RV infections are mainly transmitted due to direct contact or via fomite, with inoculation to the eye or nose from the fingertip. RV predominantly infects cells of the upper respiratory tract, although RV RNA has also been found in lower airways after experimental RV infection [3]. In situ hybridization experiments have shown that RV initially replicates in small groups of airway epithelial cells without induction of visible cytopathic effects and cell destruction $[4,5]$. RV infection does, however, compromise epithelial barrier integrity which may cause an increased translocation of pathogens and complications of respiratory diseases [6].

$\mathrm{RV}$ is the etiological agent of one-half to two-thirds of common colds [4,7]. Children can be infected from 8- to 12-times per year, while adults can be infected 2- to 3-times per year, with peaks of infection occurring throughout the year [8]. While mild and self-limiting in immunocompetent hosts, RV infection is associated with bronchiolitis in infants, pneumonia in the immunosuppressed and exacerbations of pre-existing pulmonary conditions such as asthma or chronic obstructive pulmonary disease $[9,10,11,12,13]$. Furthermore, children who experience wheezing as a result of RV infection are at increased risk of subsequently developing asthma [14]. Many of these conditions can require hospitalization and place significant economic costs upon healthcare infrastructure.

The antigenic diversity displayed by the large variety of RV serotypes has posed significant challenges for research into an effective and universal RV vaccine [15]. Currently there are in excess of ten clinical trials currently ongoing in the USA alone in an attempt to develop effective preventative vaccinations for the infection [16]. The fact that around $90 \%$ of RV serotypes bind to human ICAM-1 but cannot bind to the murine ICAM-1 receptor has, in the past, limited the availability and validity of animal models of infection [17]. However, the development of mousehuman ICAM-1 chimeras and other mouse models to study exacerbations induced by human RV, together with the availability of human experimental infections will provide avenues toward developing better therapeutics $[18,19]$. In 
addition, the significant morbidities and associated economic costs attributed to RV infections would lend weight to a global effort into the full characterization of different $\mathrm{RV}$ strains. Thus, the development of effective antivirals against the widest possible number of RV serotypes is urgently required.

\section{Antiviral drugs}

The number of established chemotherapeutic options for viral infections is still relatively low, and studies have been undertaken with a view to characterizing the anti-RV activity of drugs already licensed for use against other infections. There have been in excess of 90 antiviral drugs used for the medical treatment of viral infections, and these have been categorized into 13 functional groups (reviewed in [20]). The viral infections with antiviral treatment options include HIV, hepatitis B and C virus, herpesvirus, influenza virus, human cytomegalovirus, varicella-zoster virus, respiratory syncytial virus (RSV) and human papillomavirus. While none of these drugs have been licensed for use in RV infection, a number of existing therapeutics have been demonstrated to have antiviral activity against a number of RV serotypes and thus are exciting prospects for therapeutic use in this infection.

Ribavirin is a synthetic guanosine nucleoside that can interfere with the synthesis of viral mRNA. It is frequently used as an effective therapeutic in combination with pegylated IFN $\alpha-2 a$ for the treatment of hepatitis $\mathrm{C}$ infection and has also been used individually by clinicians in the treatment of severe lower respiratory tract infections caused by RSV [21,22]. Other infections caused by respiratory pathogens such as adenovirus have also been treated by ribavirin, normally in patients that are immunocompromised or those who have received bone marrow or stem cell transplants [23]. Coronaviruses associated with severe acute respiratory syndrome (SARS-CoV) or Middle East respiratory syndrome have also been studied in the context of ribivirin therapy, although the outcomes have been mixed, and conjunctive therapy with pegylated IFN $\alpha-2 a$ has again been suggested [24,25]. In addition, ribavirin has also been utilized in the treatment of several viral hemorrhagic fevers, caused by pathogens such as hantavirus and Lassa virus, but also in the treatment of nairovirus, the cause of the tick-borne disease Crimean-Congo hemorrhagic fever $[26,27,28]$. However, the drug is not reported to be active against Marburg virus, Ebola virus and dengue virus, and only appears to have limited activity against HSV, but not HIV [29,30,31]. In the context of RV infection, ribavirin and a number of modified analogs have been shown to have moderate antiviral activity against RV-13 [32]. RV-87 was also reported to be moderately susceptible to treatment, although other in vitro studies using alternative serotypes of RV, such as RV-14, have suggested that ribavirin is relatively ineffective [33,34]. However, clinical reports of ribavirin therapy twinned with the use of IFN $\alpha-2$ a have indicated that combinatorial therapy could be of value with patients reportedly exhibiting enhanced clearance of RV infections following treatment with these two compounds [35].

A number of studies have focused upon the effectiveness of the compound pleconaril against human RV. Pleconaril (3-(3,5-dimethyl-4-((3-(3-methyl-5-isoxazolyl)propyl)phenyl)-5-(trifluoromethyl)-1,2,4-oxadiazole) is known to display broad spectrum antiviral activity against a range of viral pathogens. It is known to bind to hydrophobic pockets within viral capsids, altering binding of the viral pathogen to host cell receptors and blocking uncoating [36]. In RV and others, this is believed to take place in the VP1 protein, the largest and most exposed surface protein of the capsid [37]. One comprehensive study examined the effectiveness of pleconaril against a selection of five RV serotypes (RV-2, RV-14, RV-16, RV-39 and RV-Hanks [later serotyped as A21]) and 46 clinical isolates using in vitro cytopathic effect (CPE) inhibition assays [38]. The study demonstrated that the compound had effective antiviral activity against the five serotypes (median EC50 of $0.02 \mu \mathrm{g} / \mathrm{ml}$ ) and against the majority of the untyped clinical isolates. Two separate studies also demonstrated findings in accord with this, showing antiviral activity of pleconaril against RV-14 and RV-87 [33,34]. Interestingly, analysis of several RV serotypes has also assessed structural features of amino acids that make up the VP1 protein, and has identified several common sequences and mutations that confer natural resistance to capsid binding compounds such as pleconaril, as well as those that could arise as a result of antiviral drug treatment [39,40]. A number of human experimental pleconaril administration studies have found that pleconaril could offer a tangible treatment option for RV infection as volunteers treated with this drug appeared to show less clinical symptomology and lower recovery of picornaviruses than controls $[41,42]$. However, varying virus serotype susceptibility to pleconaril did appear to play a significant role in the efficacy of the treatment and clinical outcome [43]. However, studies into pleconaril analogs with enhanced activity against RV are still ongoing [44].

A number of other novel capsid binding compounds have shown effective antiviral activity against rhinovirus, and another capsid binding protein that has generated intense interest is pirodavir. A study of this compound showed showed antiviral activity against RV-14 and against RV-87 [33,34]. A comprehensive assessment was undertaken by 
Brown et al. (2005), who established that pirodavir had substantial antiviral activity against a range of 15 different serotypes of RV [45]. Interestingly, RV-45 appeared to be completely resistant to this compound. However, in the same study, a series of pyridazinylpiperidinyl-based compounds were synthesized and one derivative was also found to be particularly effective against a number of the RV serotypes [45]. In a similar context, an analog of pirodavir, termed BTA798 has also shown effective activity against several RV serotypes and has been assessed in Phase II clinical trials [34,46]. Another capsid binding drug, vapendavir, which has been shown to inhibit enterovirus-71, has very recently also been utilized in Phase II clinical trials, but at the time of writing, the efficacy of this treatment is as yet unclear.

The compound rupintrivir, also known as AG7088, is an inhibitor of viral 3C protease, an enzyme that is virally encoded and essential for RV replication. Studies of rupintrivir in the context of RV infection has revealed that it exhibits moderate antiviral activity in vitro against a range of RV serotypes, enterovirus-71 and coxsackievirus [34,47,48,49,50,51]. Additionally, it demonstrated efficacy in a Phase II clinical trial of experimental RV infection and was well tolerated by human subjects in multiple human exposures [52,53]. Interestingly, a recent study has also revealed that analogs of rupintrivir based on proline and azetidine modifications to this compound have also revealed broad spectrum activity against a range of RV serotypes [54]. Of further interest was the observation that rupintrivir also exhibited in vitro activity against newly discovered human RV C strains [55]. Assessment of the potential for RV to evolve resistance to rupintrivir has also been conducted, with selection of novel RV variants in increasing concentrations of the drug displaying minimal to moderate susceptibility reductions [56]. Collectively, it is clear that this compound, and novel analogs, have potential for the development of novel therapeutics for RV, but that further in vivo trials are required.

In our literature review, we have also identified a number of other small compounds that have been investigated as novel inhibitors of RV over the past four decades. These include the compound 2-(3,4-dichlorophenoxy)-5nitrobenzonitrile (MDL-860) which showed antiviral activity against RV and other viral pathogens [57,58]. Other studies have identified novel ((biphenyloxy)propyl) isoxazole derivatives as having activity against RV-2 [59]. A very recent report describes a series of benzothiophene derivatives [60] that inhibited the replication of a number of RV serotypes and was proposed to act through viral capsid binding in a similar way to pleconaril. Recently, three novel epidithiodiketopiperazines (KCN-2,2'-epi-19, KCN-19 and KCN-21) were synthesized that displayed activity against RV-87 [33]. Interestingly, the antifungal compound itraconozole has recently been found to have in vitro and in vivo antiviral activity in RV infection [61]. This was potentially due to inhibition of cellular cholesterol trafficking, a process the authors suggest, in accord with another study [62], is essential for RV replication. This activity was retained when assessing the antiviral activity of itraconozole-loaded microemulsion droplets as carriers for the drug [63], Indeed, antiviral nanoparticles have been proposed to be excellent candidates for the development of antiviral therapeutics as their activity can extend across a broad range of pathogens [64], although further investigation on the in vivo effects of different nanoparticle formulations is required, as we have recently shown carbon nanoparticles to be capable of inhibiting the antiviral effects of the human cathelicidin, LL-37, toward RV in vitro [65].

At last, in vitro studies and clinical trials have suggested that the red seaweed polysaccharide, carrageenan, has antiviral activity against RV both in vitro and in vivo. Iota-carrageenan, a sulphated variety, was demonstrated to prevent the replication of RV-1A, 2, 8, 14, 16, 83 and 84 in nasal epithelium [66]. A clinical trial examining the effect of iota-carrageenan containing nasal spray found that patients found to be positive for RV infection and treated with nasal spray demonstrated a significant reduction in the duration of symptoms and enhanced resolution of the infection when compared with placebo control [67].

\section{Host defense peptides}

Host defense peptides (HDPs; also known as antimicrobial peptides) are key effector molecules of the innate immune response [68]. These peptides are found in many vertebrate and invertebrate organisms and display broad antimicrobial potential, acting directly on viruses and bacteria. In humans and other mammals, there are two primary families of HDPs that have been well characterized in terms of antimicrobial activity; cathelicidins and defensins.

HDPs can be expressed by leukocytes and epithelial cells, while being relatively unaffected by modern drug resistance mechanisms [69]. In addition to their powerful direct antiviral and antibacterial activity, it has also been demonstrated that these peptides possess immunomodulatory and inflammomodulatory activity and they can 
alter host cellular responses to viral infection [70]. As such, HDPs represent an exciting opportunity for naturally occurring or synthetic peptide derivatives to be used as novel therapeutic approaches for viral infection [71].

Cathelicidins are a well characterized family of HDPs with some of the most powerful antimicrobial and immunomodulatory activities. Cathelicidins are a highly conserved family of peptides found in a number of species, and represent one of the primary effector defense molecules against invading microorganisms. The sole human cathelicidin, human cathelicidin antimicrobial peptide of $18 \mathrm{kDA}$ (hCAP18), from which the active form, LL-37, is proteolytically cleaved, is primarily stored in the specific granules of neutrophils and cleaved into the active form by proteinase-3. LL-37 can also be produced and secreted by macrophages, lymphocytes and epithelial cells [72].

Studies have shown that deficiency in LL-37 in humans leads to an increased susceptibility to infection [73], and mice deficient in the murine cathelicidin (mCRAMP) also display an increased susceptibility to both bacterial and viral infections of the airway tract, skin, urinary tract and gut [74,75,76]. On the contrary, exogenous delivery of LL-37 in murine models offered enhanced clearance and reduced mortality in lethal influenza infection [77].

The antimicrobial properties of cathelicidins have been attributed to their highly cationic charge, which allows for the interaction with negatively charged bacterial and viral membranes leading to the formation of pores, and their hydrophobicity which helps the integration of the peptides into the microbial membranes. Cathelicidins have shown potent antiviral activity against a number of viruses (reviewed in [70]) but the exact mechanism of action is still not fully elucidated. It is clear that the underlying antiviral mechanism of cathelicidins appears to be partly due to direct effects on the virus envelope, and this has been extensively shown in in vitro studies. Both LL-37, and the murine cathelicidin mCRAMP, have shown the ability to damage the viral envelope of vaccinia virus, influenza A virus (IAV) and HSV [77,78,79,80]. LL-37 has also been shown to target viral envelope proteins inhibiting dengue virus entry into host cells [81].

However, studies have also revealed that cathelicidins have the ability to inactivate nonenveloped viruses, such as adenovirus and RV [70,80,82]. In the context of RV, it was found that optimal inhibition of virus replication was reached when the virus was directly exposed to the peptide prior to infection of cells. However, studies with other viral pathogens have shown that host cell pretreatment or delayed treatment with exogenous LL-37 also inhibited RSV and IAV replication to an extent $[83,84,85]$. In vivo studies have also demonstrated the ability of LL-37 to modulate inflammatory responses to viral infections by inhibiting excessive inflammation in IAV-infected mice [77]. This indicates that the mechanisms underpinning cathelicidins antiviral activity are complex and that direct interaction with virus particles allows peptide-mediated damage of, or binding to, the viral envelope may be a key requirement for this activity. However, interactions with host cells and modulation of the inflammatory and innate antiviral response could also be of critical importance in the activities of these peptides.

We and others have shown that exogenous LL-37, or vitamin D-mediated cathelicidin production, has potent direct antiviral activity against RV $[82,86,87]$, including cathelicidins from other mammalian species, such as the porcine cathelicidin, protegrin-1, and the ovine cathelicidin SMAP-29 [82]. This indicates that the antiviral activity of cathelicidins is not species-specific against human RV. To further investigate the mechanism underpinning LL-37 activity, we assessed the ability of LL-37 to induce cell death in RV-infected airway epithelial cells as previously we had reported that LL-37 induced apoptotic cell death of Pseudomonas aeruginosa-infected lung epithelial cells [88]. In contrast to these observations, LL-37 did not induce apoptosis or necrosis in RV-infected airway epithelial cells [82]. In addition to its direct antiviral activity, LL-37 has also shown the ability to modulate inflammation [89], which may prove to be a key property in the development of therapeutics that modulate the inflammatory response to viral infections.

Vitamin D is known for its positive effects on bone mineralization and calcium metabolism, and severe deficiency has classically been linked to rickets. Mounting evidence now points to a key immunomodulatory role for vitamin D and to a link between vitamin D deficiency and increased susceptibility to acute viral infections [90]. Furthermore, despite conflicting reports and heterogeneity within studies, a recent systematic review encompassing 10933 participants in 25 randomized controlled trials concluded that vitamin D supplementation reduced the risk of acute respiratory infection, with stronger protective effects in patients with baseline 25 -hydroxyvitamin D levels $<25 \mathrm{nmol} / 1$ [91].

Humans primarily obtain vitamin D from solar exposure and from the diet. Solar ultraviolet B radiation converts 7-dehydrocholesterol to previtamin D3, which is rapidly converted to vitamin D3. Vitamin D3 from the skin or the diet is further converted to 25-hydroxyvitamin- $\mathrm{D}$ which circulates in serum and is used to determine the vitamin D status. Lung epithelial cells and immune cells can convert the circulating, inactive, 25-hydroxyvitamin-D to 


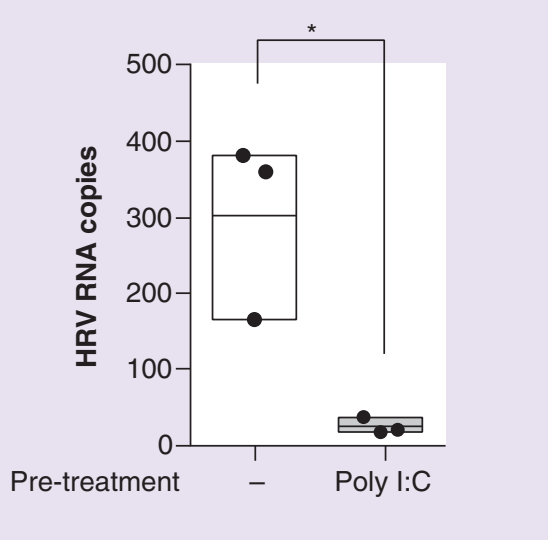

Figure 1. Poly I:C treatment of lung epithelial cell prior to infection with human RV 1B reduces viral replication. Human bronchial epithelial $\left(16 \mathrm{HBE} 14^{\circ-}\right)$ cells were treated with 10 $\mu \mathrm{g} / \mathrm{ml}$ Poly I:C for $24 \mathrm{~h}$, prior to infection with RV1B (MOI 5) and incubation for $24 \mathrm{~h}$. Viral RNA copies were quantified by RT-PCR. Figure is representative of $n=3$ independent experiments and shows total virus RNA copy number compared with control (untreated). Statistical analysis was performed using a t-test to compare virus only (untreated) control with virus + Poly I:C pretreatment $\left({ }^{*} p \leq 0.05\right)$.

RT-PCR: Reverse transcription-polymerase chain reaction.

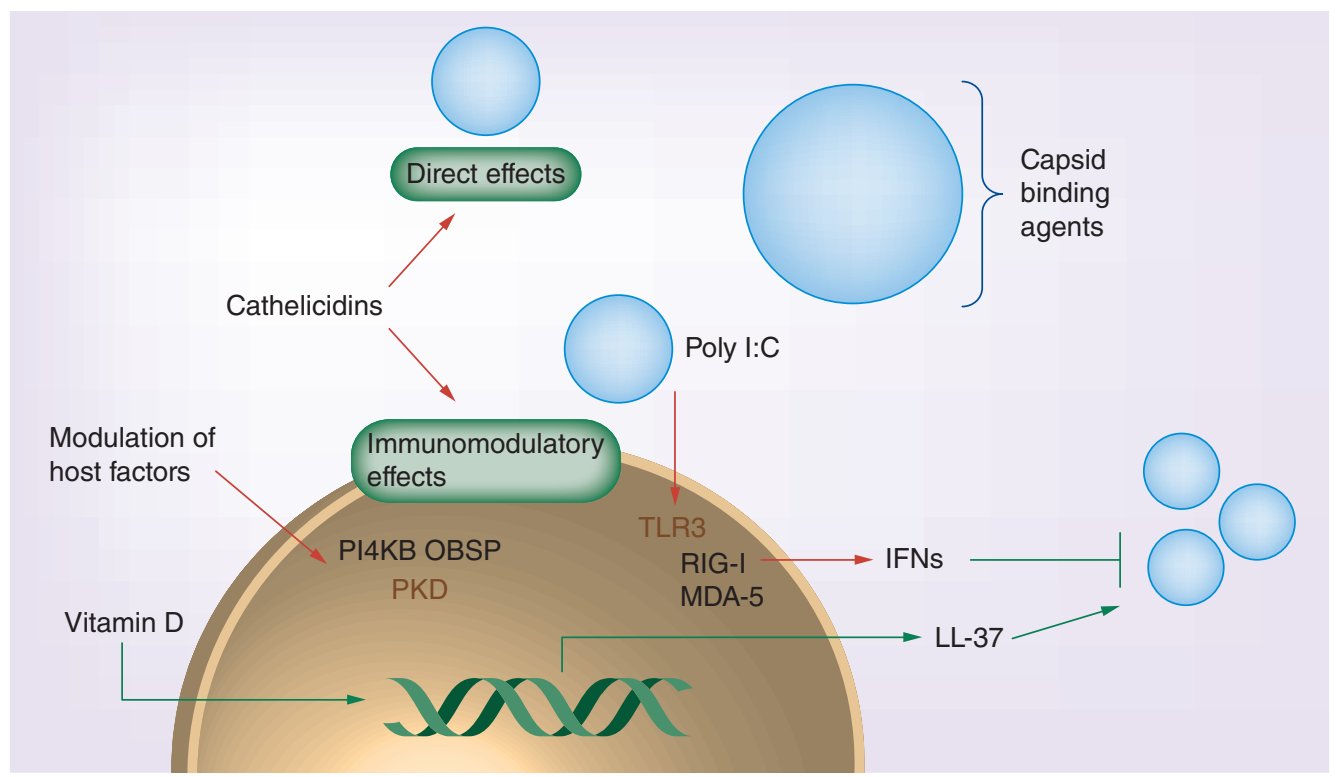

Figure 2. Schematic representation of targets for development of antiviral therapeutics against human RV.

its active form, $1,25(\mathrm{OH})_{2} \mathrm{D}$ or calcitriol, which can engage the nuclear vitamin $\mathrm{D}$ receptor (VDR) and mediate its myriad of actions [92,93,94], revealing an important health problem and the underscoring the possibility of intervention by vitamin $\mathrm{D}$ supplementation.

The immediate consequence of nuclear VDR ligation is the heterodimerization with retinoid X receptor and the binding to vitamin $\mathrm{D}$ responsive elements in promoter regions of responsive genes. These genes include CAMP and DEFB4, which correspond to human cationic antimicrobial peptide of $18 \mathrm{KDa}$ (hCAP-18/LL-37) and $\beta$ Defensin-2 (HBD2) of which both are HDPs [95]. Induction of LL-37 by vitamin D has been reported in several cell types, including lung epithelial cells, and of relevance, calcitriol $\left(1,25-(\mathrm{OH})_{2} \mathrm{D}_{3}\right)$ delivery to human primary bronchial epithelial cells (HPBEC) $24 \mathrm{~h}$ prior to RV-16 infection proved sufficient to reduce viral replication by 2.8-fold in comparison to untreated cells [86]. This effect was also observed in cells from cystic fibrosis patients with a twofold reduction in virus. Importantly, $C A M P$ but not $D E F B 4 \mathrm{mRNA}$ expression was increased by vitamin $\mathrm{D}$, and exogenous delivery of $20 \mu \mathrm{g} / \mathrm{ml}$ of recombinant LL-37 recapitulated the antiviral effects observed with vitamin D delivery. A subsequent study validated the antiviral effect of calcitriol pretreatment on the RV1B serotype, reducing both viral RNA and virion release from HPBEC [87]. These two studies show that calcitriol induces LL-37 and that $>20 \mu \mathrm{g} / \mathrm{ml}$ of exogenous LL-37 have a direct antiviral effect on RV, an activity that is conserved to other mammal cathelicidins [82]. 
When a complex and physiological model of fully differentiated HPBEC in an air-liquid interface was used to address the effects of calcitriol on RV16 replication, no reduction in viral load was observed [96]. However, clear effects on cell morphology and replication were noted. While the doses of calcitriol used in this study were lower $(10 \mathrm{nM})$ than above mentioned studies, these differences underscore the importance of the cell and delivery system used to study vitamin D effects. In this regard, daily delivery of $2 \mu \mathrm{g}$ of calcitriol in tablet form for 1 week failed to significantly increase nasal LL-37 concentrations in a double-blind, placebo-controlled study involving healthy or asthmatic subjects [97]. Interestingly, the same group reported that exposing fully differentiated HPBEC to proinflammatory cytokines such as TNF- $\alpha$ and IL- $1 \beta$, prior to vitamin D treatment, lessened the induction of LL-37. This reduced the overall antimicrobial effects of vitamin D due to an alteration in the metabolic pathway [98]. These observations indicate that further work in this area is required, particularly in the context of chronic inflammatory lung diseases, as this finding could limit the benefits of vitamin D supplementation strategies.

Upregulation of endogenous HDP production or the delivery of exogenous cathelicidins or synthetic analogs represents novel and exciting therapeutic strategies for protecting and treating human RV infections. There is therefore a need to further investigate the mechanisms behind their ability to inhibit viral infections, and to further establish the antiRV activity of other families of peptides, including defensins. Understanding how these small peptides operate could support the development of novel therapeutic strategies for RV and possibly other viral infections.

\section{Modulation of the host response}

Modulation or targeting of host molecules responsible for facilitating infection and viral replication may also provide a valuable therapeutic avenue for the therapeutic treatment of RV. One area of interest has focused upon the innate antiviral response, which results in broad range protection from infection, and was attributed to interferons [99]. Purification and further study of interferons found that they were devoid of inherent antiviral activity, but stimulated the production of other antiviral molecules [100,101], which led coining of the phrase 'antiviral state'. Upon recognition of pathogens by cellular sensors including TLRs and RLRs, the type I IFNs (IFN- $\alpha$ and IFN- $\beta$ ) and type III IFNs (IFN- $\lambda$ ) are some of the earliest immune mediators to be produced (reviewed in [102]). Their subsequent binding to the interferon receptor induces expression of several interferon-stimulated genes, resulting in powerful antiviral and immunomodulatory effects to limit infection [103]. Features of this induced antiviral state include resistance to viral replication, induction of apoptotic cell death and increased expression of major histocompatibility complex class I in infected cells. Interferons also have an impact on immune cells, activating dendritic cells (DCs) and macrophages, and stimulating NK cells to enhance their cytolytic activity [104]. This multifaceted, broad-spectrum protection is key to successful antiviral responses.

Recent studies have shown that RV is detected by different sensors on or within the host cell; components of the capsid are detected by TLR2; ssRNA genome is detected by TLR7/8 and dsRNA generated during viral replication is detected by TLR3 in endosomes or RIG-I and MDA5 in the cytosol $[105,106]$. TLR3 is constitutively expressed in lung epithelial cells, whereas RIG-I and MDA5 are upregulated in response to infection $[107,108]$. Importantly, gene silencing any of the dsRNA sensors using siRNA reduces the cytokine response and increases RV replication, suggesting a coordinated role for multiple sensors in antiviral responses to RV [109]. In this context, mice lacking TLR3 exhibit higher loads of RNA viruses and decreased production of type I IFN compared with wild-type mice $[110,111]$. Significantly, a case study reported that a child harboring a homozygous missense mutation in the gene IFIH1, which encodes for MDA5, was highly susceptible to recurrent and life-threatening RV infections [112]. This gene mutation resulted in failure to recognize MDA5-ligands associated with RV infection, leading to reduced IFN production and therefore increased susceptibility to RV.

In vitro studies have shown that exogenous delivery of $0.1-10 \mathrm{ng} / \mathrm{ml}$ interferons (IFN- $\alpha$, IFN- $\beta$, IFN- $\lambda 1$ or IFN- $\lambda 2$ ) reduced RV1A viral copies in HPBECs [113]. Interestingly, the exogenous addition of IFN- $\beta$ also suppressed RV16 and RV1B replication in HPBECs isolated from healthy and asthmatic individuals [114,115,116,117]. However, exogenous IFN delivery can also potentially impact the already elevated cytokine levels found during RV infection [113], thus caution must be exercised with this therapeutic strategy.

Polyinosinic-polycytidylic acid, commonly referred to as Poly I:C, is a dsRNA structure that mimics intermediates generated during viral replication. When sensed by TLR-3 or cytoplasmic RLR sensors (MAD5 and RIG-I), Poly $\mathrm{I}: \mathrm{C}$ induces a strong interferon response, and prophylactic administration of Poly I:C in vitro or in vivo can enhance protection against a number of viral infections, including several strains of RV [118,119,120,121]. 
In addition to regulating the interferon response, Poly I:C is a powerful inducer of proinflammatory cytokines and chemokines and has been linked to maturation of DCs, NK cell cytotoxicity and virus-specific T-cell responses $[122,123]$. This amplification of innate and adaptive immunity provides protection against a range of viruses, including influenza, Rift Valley fever virus, rabies virus, SARS-Co-BV and RSV [124,125,126,127,128]. Data from our own laboratory has shown that pretreatment of bronchial epithelial cells with $10 \mu \mathrm{g} / \mathrm{ml}$ of Poly I:C substantially affects RV RV1B replication (Figure 1).

Drugs based on Poly I:C or derivatives are being developed as broad-spectrum antivirals and potential adjuvants for DC-targeted vaccines. Poly I:C stabilized with poly-l-lysine and carboxymethylcellulose, known as poly-ICLC, has shown efficacy against viruses such as influenza [129] and is also being tested in an HIV vaccine trial (Oncovir, Inc. and Dalton Pharma Services, ON, Canada). PIKA (NewBiomed PIKA Pte Ltd, Singapore), a chemically stabilized analog of Poly I:C also reduced influenza virus load in the lungs of infected mice [130]. While its antiviral effects hold promise for treatment of RV infection, delivery of Poly I:C can, in some instances, lead to increased bacterial replication (Mycobacterium tuberculosis, Streptococcus pneumoniae and Staphylococcus aureus) and impaired clearance from the lungs due to prolonged interferon signaling $[131,132]$. Given that RV is frequently associated with increased secondary bacterial infections, especially in individuals with chronic obstructive pulmonary disease or other underlying morbidities, further work is required to determine whether Poly I:C or stabilized analogs are safe as antiviral therapeutics for RV infection.

A further therapeutic strategy may be targeting of host factors that have been identified as important in the context of RV replication. For example, both oxysterol binding protein (OSBP) and phosphatidylinositol 4-kinase III $\beta$ (PI4KB), have been identified as host proteins involved in picornavirus replication $[133,134,135]$, and studies focusing upon chemical inhibition of PI4KB with a panel of aminothiazoles have demonstrated potent inhibition of RV [136]. Equally, novel enviroxime-like compounds as well as other compounds such as itraconozole (mentioned above) which can target OSBP have also shown promise in inhibiting viral replication $[61,62,134,137]$. Furthermore, as both PI4KB and OSBP can act as substrates for protein kinase D (PKD), recent studies have identified PKD as a key molecule in RV replication and have demonstrated that PKD inhibition can profoundly affect RV replication at an early stage [138]. Interestingly, the lipid-modifying enzyme PLA2G16 has recently been described as playing a role in picornavirus replication through enhanced viral protein synthesis [139]. Of note, a very recent study reported that a novel compound, termed IMP-1088, showed potent inhibitory activity towards multiple strains of RV at nanomolar concentrations. This particular compound blocked viral replication by targeting the host cell N-myristoyltransferases NMT1 and NMT2, which are required for the assembly of the viral capsid [140]. Thus, therapeutic options targeting inhibition or functional modulation of these enzymes, or others involved in viral protein synthesis, may be of value.

\section{Neutralizing antibodies}

RV ssRNA genome is contained within an icosahedral protein capsid comprised of four structural proteins; three are surface exposed (VP1, VP2 and VP3), and VP4 is buried [141]. RV-specific neutralizing antibodies have been developed against epitopes found on VP proteins that aim to block virus-receptor interaction, stabilize the capsid preventing viral uncoating, or cause conformational changes in the capsid inducing premature genome release $[142,143,144]$. Other studies have shown that antibodies raised against VP4, specifically the N terminus, had RV neutralizing activity and, indeed, may be a promising target for therapeutic development $[145,146]$. Another approach has been to develop antibodies that bind to the host cell receptors, thereby blocking entry of RV. Targeting ICAM-1 in transgenic mice engineered to overexpress extracellular domains 1 and 2 of human ICAM-1 has been shown to prevent the entry of two major groups of RV, RV16 and RV14. Reduced cellular inflammation, proinflammatory cytokine production and virus load was also observed in this model [147]. However, targeting and blockage of other receptors used by minor group RV, such as the low-density lipoprotein (LDL) receptor, has proved elusive. This is also the case in the context of the development of a universal 'anti-RV' antibody, which is problematic due to the antigenic diversity of circulating RV. Thus, there remain significant challenges associated with the identification of new antigenic variants and the fact that around $90 \%$ of RV serotypes cannot bind to the murine ICAM- 1 receptor.

Development of antibody therapies for the prevention and treatment of other viral infections has been recently reviewed with several antibodies undergoing preclinical development or in clinical trials for newly emerging viral pathogens such as Ebola as well as long standing pathogens such as influenza [148]. At present there are no licensed antibodies for clinical use in RV infection, underscoring the need for alternative therapeutic strategies. 


\section{Conclusion \& future perspective}

An effective licensed therapeutic treatment for RV remains elusive, despite several decades of intensive work that has aimed to characterize the activity of a wide range of naturally occurring and synthetic compounds against this infection. The answer to this problem may lie in manipulation of the host cell response with a view to inhibiting RV replication and spread. For example, one recent study that screened 50,000 potential antiviral structures, and subsequently identified and analyzed the compound FA-613 found that it interferes with intracellular pyrimidine synthesis pathways [149]. Furthermore, the addition of FA-613 to virus-infected cells induced the elevated expression of antiviral genes, leading to inhibition of RV, influenza, RSV and coronavirus replication. This is an example of a host-cell focused strategy that could yield promising results in the future.

Another way forward could be the use of peptides that are able to act by blocking receptors, such as ICAM- 1 and LDL, essential for RV binding and entry. Cathelicidins can inactivate nonenveloped viruses, such as adenovirus, and optimal inhibition of RV replication occurs when the virus is directly exposed to the peptide, suggesting that peptide binding to a component of the capsid is occurring [70,82]. At present, virtually nothing is known about the determinants for cathelicidin binding to the viral capsid and a full understanding of this will require fine mapping of cathelicidin binding sites and identification of the active peptide region.

Many of the therapeutics described herein have been under investigation for decades, but the challenges posed by this particular pathogen have, thus far, been insurmountable. Encouragingly, a new wave of antiviral peptides and compounds has been characterized over the past 2-3 years, and thus the potential for developing novel and effective treatments for targeting RV infection may be closer than ever before (Figure 2).

\section{Executive summary}

\section{Human rhinoviruses}

- Human rhinoviruses (RVs) are the primary etiological agents of the common cold, but can cause serious illness and increased hospital admissions in immunocompromised individuals or those with pre-existing respiratory conditions.

- There is currently no licensed vaccine for RV due to the challenges posed by the antigenic diversity and large variety of circulating RV serotypes.

\section{Antiviral drugs}

- There are a number of broad spectrum antiviral drugs that have been shown to display inhibitory activity against RV.

- Many of the drugs that have shown the most effective activity are capsid binding compounds.

Host defense peptides

- Host defense peptides, such as cathelicidins, are key components of the mammalian immune system and many display powerful antiviral activity.

- Cathelicidins from a number of mammalian species possess antiviral activity toward RV.

- Vitamin D metabolites can upregulate host defense molecules and in vitro supplementation in models of RV infection has been reported to reduce viral replication.

Modulation of the host response

- Interferon is critical in the immune response to RV, and manipulation of the interferon response using exogenous viral mimics, such as Poly I:C, has been shown to reduce RV replication.

- Identification of host molecules required for viral replication can provide novel targets for antiviral therapy and compounds that can target these host factors have been shown to affect RV replication.

Future perspective

- Investigation of novel capsid binding compounds or peptides will likely be a key determinant in finding an effective therapeutic for RV.

- Development of novel therapeutics that interfere with RV binding, entry and replication in the host cell could yield promising results. 


\section{Ethical conduct of research}

The authors state that they have obtained appropriate institutional review board approval or have followed the principles outlined in the Declaration of Helsinki for all human or animal experimental investigations. In addition, for investigations involving human subjects, informed consent has been obtained from the participants involved.

\section{Open access}

This work is licensed under the Attribution-NonCommercial-NoDerivatives 4.0 Unported License. To view a copy of this license, visit http://creativecommons.org/licenses/by-nc-nd/4.0/

\section{References}

1. Palmenberg AC, Rathe JA, Liggett SB. Analysis of the complete genome sequences of human rhinovirus. J. Allergy Clin. Immunol. 125(6), 1190-1201 (2010).

2. Bochkov YA, Watters K, Ashraf S et al. Cadherin-related family member 3, a childhood asthma susceptibility gene product, mediates rhinovirus C binding and replication. Proc. Natl Acad. Sci. USA 112(17), 5485-5490 (2015).

3. Gern JE, Galagan DM, Jarjour NN, Dick EC, Busse WW. Detection of rhinovirus RNA in lower airway cells during experimentally induced infection. Am. J. Respir. Crit. Care Med. 155(3), 1159-1161 (1997).

4. Arruda E, Boyle TR, Winther B, Pevear DC, Gwaltney JM Jr, Hayden FG. Localization of human rhinovirus replication in the upper respiratory tract by in situ hybridization. J. Infect. Dis. 171(5), 1329-1333 (1995).

5. Winther B, Gwaltney JM, Hendley JO. Respiratory virus infection of monolayer cultures of human nasal epithelial cells. Am. Rev. Respir. Dis. 141(4 Pt 1), 839-845 (1990).

6. Sajjan U, Wang Q, Zhao Y, Gruenert DC, Hershenson MB. Rhinovirus disrupts the barrier function of polarized airway epithelial cells. Am. J. Respir. Crit. Care Med. 178(12), 1271-1281 (2008).

7. Makela MJ, Puhakka T, Ruuskanen O et al. Viruses and bacteria in the etiology of the common cold. J. Clin. Microbiol. 36(2), 539-542 (1998).

8. Turner RB. Epidemiology, pathogenesis, and treatment of the common cold. Ann. Allergy Asthma Immunol. 78(6), 531-539 (1997).

9. Jartti T, Gern JE. Rhinovirus-associated wheeze during infancy and asthma development. Curr. Respir. Med. Rev. 7(3), 160-166 (2011).

10. Kaiser L, Aubert JD, Pache JC et al. Chronic rhinoviral infection in lung transplant recipients. Am. J. Respir. Crit. Care Med. 174(12), 1392-1399 (2006).

11. Corne JM, Marshall C, Smith S et al. Frequency, severity, and duration of rhinovirus infections in asthmatic and non-asthmatic individuals: a longitudinal cohort study. Lancet 359(9309), 831-834 (2002).

12. Johnston SL, Pattemore PK, Sanderson G et al. Community study of role of viral infections in exacerbations of asthma in 9-11 year old children. BMJ 310(6989), 1225-1229 (1995).

13. Papi A, Bellettato CM, Braccioni F et al. Infections and airway inflammation in chronic obstructive pulmonary disease severe exacerbations. Am. J. Respir. Crit. Care Med. 173(10), 1114-1121 (2006).

14. Gavala ML, Bertics PJ, Gern JE. Rhinoviruses, allergic inflammation, and asthma. Immunol. Rev. 242(1), 69-90 (2011).

15. Glanville N, Johnston SL. Challenges in developing a cross-serotype rhinovirus vaccine. Curr. Opin. Virol. 11, 83-88 (2015).

16. Tang JW, Lam TT, Zaraket H et al. Global epidemiology of non-influenza RNA respiratory viruses: data gaps and a growing need for surveillance. Lancet Infect. Dis. 17(10), e320-e326 (2017).

17. Register RB, Uncapher CR, Naylor AM, Lineberger DW, Colonno RJ. Human-murine chimeras of ICAM-1 identify amino acid residues critical for rhinovirus and antibody binding. J. Virol. 65(12), 6589-6596 (1991).

18. Bartlett NW, Walton RP, Edwards MR et al. Mouse models of rhinovirus-induced disease and exacerbation of allergic airway inflammation. Nat. Med. 14(2), 199-204 (2008).

19. Mallia P, Message SD, Gielen V et al. Experimental rhinovirus infection as a human model of chronic obstructive pulmonary disease exacerbation. Am. J. Respir. Crit. Care Med. 183(6), 734-742 (2011).

20. De Clercq E, Li G. Approved antiviral drugs over the past 50 years. Clin. Microbiol. Rev. 29(3), 695-747 (2016).

21. Trang TP, Whalen M, Hilts-Horeczko A, Doernberg SB, Liu C. Comparative effectiveness of aerosolized versus oral ribavirin for the treatment of respiratory syncytial virus infections: a single-center retrospective cohort study and review of the literature. Transpl. Infect. Dis. 20(2), e12844 (2018).

22. Abonyi ME, Lakatos PL. Ribavirin in the treatment of hepatitis C. Anticancer Res. 25(2B), 1315-1320 (2005).

23. Grim SA, Reid GE, Clark NM. Update in the treatment of non-influenza respiratory virus infection in solid organ transplant recipients. Expert Opin. Pharmacother. 18(8), 767-779 (2017).

24. Mo Y, Fisher D. A review of treatment modalities for Middle East Respiratory Syndrome. J. Antimicrob. Chemother. 71(12), 3340-3350 (2016). 
25. Wong SS, Yuen KY. The management of coronavirus infections with particular reference to SARS. J. Antimicrob. Chemother. 62(3), 437-441 (2008).

26. Szabo R. Antiviral therapy and prevention against hantavirus infections. Acta Virol. 61(1), 3-12 (2017).

27. Mccormick JB, King IJ, Webb PA et al. Lassa fever. Effective therapy with ribavirin. N. Engl. J. Med. 314(1), 20-26 (1986).

28. Fisher-Hoch SP, Khan JA, Rehman S, Mirza S, Khurshid M, Mccormick JB. Crimean Congo-haemorrhagic fever treated with oral ribavirin. Lancet 346(8973), 472-475 (1995).

29. Borio L, Inglesby T, Peters CJ et al. Hemorrhagic fever viruses as biological weapons: medical and public health management. JAMA 287(18), 2391-2405 (2002).

30. Multicenter clinical trial of oral ribavirin in symptomatic HIV-infected patients. The Ribavirin ARC Study Group. J. Acquir. Immune Defic. Syndr. 6(1), 32-41 (1993).

31. Bierman SM, Kirkpatrick W, Fernandez H. Clinical efficacy of ribavirin in the treatment of genital herpes simplex virus infection. Chemotherapy 27(2), 139-145 (1981)

32. Allen LB, Boswell KH, Khwaja TA et al. Synthesis and antiviral acticity of some phosphates of the broad-spectrum antiviral nucleoside, 1-beta-D-ribofuranosyl-1,2,4-triazole-3-carboxamide (ribavirin). J. Med. Chem. 21(8), 742-746 (1978).

33. Smee DF, Evans WJ, Nicolaou KC, Tarbet EB, Day CW. Susceptibilities of enterovirus D68, enterovirus 71, and rhinovirus 87 strains to various antiviral compounds. Antiviral Res. 131, 61-65 (2016).

34. Thibaut HJ, Leyssen P, Puerstinger G, Muigg A, Neyts J, De Palma AM. Towards the design of combination therapy for the treatment of enterovirus infections. Antiviral Res. 90(3), 213-217 (2011).

35. Ruuskanen O, Waris M, Kainulainen L. Treatment of persistent rhinovirus infection with pegylated interferon alpha2a and ribavirin in patients with hypogammaglobulinemia. Clin. Infect. Dis. 58(12), 1784-1786 (2014).

36. Reisdorph N, Thomas JJ, Katpally U et al. Human rhinovirus capsid dynamics is controlled by canyon flexibility. Virology 314(1), 34-44 (2003).

37. Smith TJ, Kremer MJ, Luo M et al. The site of attachment in human rhinovirus 14 for antiviral agents that inhibit uncoating. Science 233(4770), 1286-1293 (1986).

38. Kaiser L, Crump CE, Hayden FG. In vitro activity of pleconaril and AG7088 against selected serotypes and clinical isolates of human rhinoviruses. Antiviral Res. 47(3), 215-220 (2000).

39. Ledford RM, Patel NR, Demenczuk TM et al. VP1 sequencing of all human rhinovirus serotypes: insights into genus phylogeny and susceptibility to antiviral capsid-binding compounds. J. Virol. 78(7), 3663-3674 (2004).

40. Ledford RM, Collett MS, Pevear DC. Insights into the genetic basis for natural phenotypic resistance of human rhinoviruses to pleconaril. Antiviral Res. 68(3), 135-138 (2005).

41. Hayden FG, Coats T, Kim K et al. Oral pleconaril treatment of picornavirus-associated viral respiratory illness in adults: efficacy and tolerability in phase II clinical trials. Antivir. Ther. (Lond.) 7(1), 53-65 (2002).

42. Hayden FG, Herrington DT, Coats TL et al. Efficacy and safety of oral pleconaril for treatment of colds due to picornaviruses in adults: results of 2 double-blind, randomized, placebo-controlled trials. Clin. Infect. Dis. 36(12), 1523-1532 (2003).

43. Pevear DC, Hayden FG, Demenczuk TM, Barone LR, Mckinlay MA, Collett MS. Relationship of pleconaril susceptibility and clinical outcomes in treatment of common colds caused by rhinoviruses. Antimicrob. Agents Chemother. 49(11), 4492-4499 (2005).

44. Lacroix C, Laconi S, Angius $\mathrm{F}$ et al. In vitro characterisation of a pleconaril/pirodavir-like compound with potent activity against rhinoviruses. Virol. J. 12, 106 (2015).

45. Brown RN, Cameron R, Chalmers DK et al. 2-Ethoxybenzoxazole as a bioisosteric replacement of an ethyl benzoate group in a human rhinovirus (HRV) capsid binder. Bioorg. Med. Chem. Lett. 15(8), 2051-2055 (2005).

46. Feil SC, Hamilton S, Krippner GY et al. An orally available 3-ethoxybenzisoxazole capsid binder with clinical activity against human rhinovirus. ACS Med. Chem. Lett. 3(4), 303-307 (2012).

47. Binford SL, Maldonado F, Brothers MA et al. Conservation of amino acids in human rhinovirus 3C protease correlates with broad-spectrum antiviral activity of rupintrivir, a novel human rhinovirus 3C protease inhibitor. Antimicrob. Agents Chemother. 49(2), 619-626 (2005).

48. Patick AK, Binford SL, Brothers MA et al. In vitro antiviral activity of AG7088, a potent inhibitor of human rhinovirus 3C protease. Antimicrob. Agents Chemother. 43(10), 2444-2450 (1999).

49. Matthews DA, Dragovich PS, Webber SE et al. Structure-assisted design of mechanism-based irreversible inhibitors of human rhinovirus 3C protease with potent antiviral activity against multiple rhinovirus serotypes. Proc. Natl Acad. Sci. USA 96(20), 11000-11007 (1999).

50. Lu G, Qi J, Chen Z et al. Enterovirus 71 and coxsackievirus A16 3C proteases: binding to rupintrivir and their substrates and anti-hand, foot, and mouth disease virus drug design. J. Virol. 85(19), 10319-10331 (2011).

51. Lee ES, Lee WG, Yun SH et al. Development of potent inhibitors of the coxsackievirus 3C protease. Biochem. Biophys. Res. Commun. 358(1), 7-11 (2007). 
52. Hayden FG, Turner RB, Gwaltney JM et al. Phase II, randomized, double-blind, placebo-controlled studies of ruprintrivir nasal spray 2-percent suspension for prevention and treatment of experimentally induced rhinovirus colds in healthy volunteers. Antimicrob. Agents Chemother. 47(12), 3907-3916 (2003).

53. Hsyu PH, Pithavala YK, Gersten M, Penning CA, Kerr BM. Pharmacokinetics and safety of an antirhinoviral agent, ruprintrivir, in healthy volunteers. Antimicrob. Agents Chemother. 46(2), 392-397 (2002).

54. Kawatkar SP, Gagnon M, Hoesch V et al. Design and structure-activity relationships of novel inhibitors of human rhinovirus 3C protease. Bioorg. Med. Chem. Lett. 26(14), 3248-3252 (2016).

55. Mello $\mathrm{C}$, Aguayo E, Rodriguez $\mathrm{M}$ et al. Multiple classes of antiviral agents exhibit in vitro activity against human rhinovirus type $\mathrm{C}$. Antimicrob. Agents Chemother. 58(3), 1546-1555 (2014).

56. Binford SL, Weady PT, Maldonado F, Brothers MA, Matthews DA, Patick AK. In vitro resistance study of rupintrivir, a novel inhibitor of human rhinovirus 3C protease. Antimicrob. Agents Chemother. 51(12), 4366-4373 (2007).

57. Powers RD, Gwaltney JM Jr., Hayden FG. Activity of 2-(3,4-dichlorophenoxy)-5-nitrobenzonitrile (MDL-860) against picornaviruses in vitro. Antimicrob. Agents Chemother. 22(4), 639-642 (1982).

58. Torney HL, Dulworth JK, Steward DL. Antiviral activity and mechanism of action of 2-(3,4-dichlorophenoxy)-5-nitrobenzonitrile (MDL-860). Antimicrob. Agents Chemother. 22(4), 635-638 (1982).

59. Makarov VA, Riabova OB, Granik VG, Wutzler P, Schmidtke M. Novel [(biphenyloxy)propyl]isoxazole derivatives for inhibition of human rhinovirus 2 and coxsackievirus B3 replication. J. Antimicrob. Chemother. 55(4), 483-488 (2005).

60. Kim J, Jung YK, Kim C et al. A novel series of highly potent small molecule inhibitors of rhinovirus replication. J. Med. Chem. 60(13), 5472-5492 (2017).

61. Shim A, Song JH, Kwon BE et al. Therapeutic and prophylactic activity of itraconazole against human rhinovirus infection in a murine model. Sci. Rep. 6, 23110 (2016).

62. Strating JR, Van Der Linden L, Albulescu L et al. Itraconazole inhibits enterovirus replication by targeting the oxysterol-binding protein. Cell Rep. 10(4), 600-615 (2015).

63. Lee JJ, Shim A, Jeong JY, Lee SY, Ko HJ, Cho HJ. Development of intranasal nanovehicles of itraconazole and their immunological activities for the therapy of rhinovirus infection. Colloids Surf. B Biointerfaces 143, 336-341 (2016).

64. Cagno V, Andreozzi P, D’alicarnasso $\mathrm{M}$ et al. Broad-spectrum non-toxic antiviral nanoparticles with a virucidal inhibition mechanism. Nat. Mater. 17(2), 195-203 (2018).

65. Findlay F, Pohl J, Svoboda P et al. Carbon nanoparticles inhibit the antimicrobial activities of the human cathelicidin LL-37 through structural alteration. J. Immunol. 199(7), 2483-2490 (2017).

66. Grassauer A, Weinmuellner R, Meier C, Pretsch A, Prieschl-Grassauer E, Unger H. Iota-Carrageenan is a potent inhibitor of rhinovirus infection. Virol. J. 5, 107 (2008).

67. Koenighofer M, Lion T, Bodenteich A et al. Carrageenan nasal spray in virus confirmed common cold: individual patient data analysis of two randomized controlled trials. Multidiscip. Respir. Med. 9(1), 57 (2014).

68. Zasloff M. Antimicrobial peptides of multicellular organisms. Nature 415(6870), 389-395 (2002).

69. Bowdish DM, Davidson DJ, Hancock RE. Immunomodulatory properties of defensins and cathelicidins. Curr. Top. Microbiol. Immunol. 306, 27-66 (2006).

70. Barlow PG, Findlay EG, Currie SM, Davidson DJ. Antiviral potential of cathelicidins. Future Microbiol. 9(1), 55-73 (2014).

71. Gwyer Findlay E, Currie SM, Davidson DJ. Cationic host defence peptides: potential as antiviral therapeutics. BioDrugs 27(5), 479-493 (2013).

72. Agerberth B, Charo J, Werr J et al. The human antimicrobial and chemotactic peptides LL-37 and alpha-defensins are expressed by specific lymphocyte and monocyte populations. Blood 96(9), 3086-3093 (2000).

73. Putsep K, Carlsson G, Boman HG, Andersson M. Deficiency of antibacterial peptides in patients with morbus Kostmann: an observation study. Lancet 360(9340), 1144-1149 (2002).

74. Chromek M, Slamova Z, Bergman P et al. The antimicrobial peptide cathelicidin protects the urinary tract against invasive bacterial infection. Nat. Med. 12(6), 636-641 (2006).

75. Iimura M, Gallo RL, Hase K, Miyamoto Y, Eckmann L, Kagnoff MF. Cathelicidin mediates innate intestinal defense against colonization with epithelial adherent bacterial pathogens. J. Immunol. 174(8), 4901-4907 (2005).

76. Yu FS, Cornicelli MD, Kovach MA et al. Flagellin stimulates protective lung mucosal immunity: role of cathelicidin-related antimicrobial peptide. J. Immunol. 185(2), 1142-1149 (2010).

77. Barlow PG, Svoboda P, Mackellar A et al. Antiviral activity and increased host defense against influenza infection elicited by the human cathelicidin LL-37. PLoS ONE 6(10), e25333 (2011).

78. Dean SN, Bishop BM, Van Hoek ML. Natural and synthetic cathelicidin peptides with anti-microbial and anti-biofilm activity against Staphylococcus aureus. BMC Microbiol. 11, 114 (2011). 
79. Howell MD, Jones JF, Kisich KO, Streib JE, Gallo RL, Leung DY. Selective killing of vaccinia virus by LL-37: implications for eczema vaccinatum. J. Immunol. 172(3), 1763-1767 (2004).

80. Gordon YJ, Huang LC, Romanowski EG, Yates KA, Proske RJ, Mcdermott AM. Human cathelicidin (LL-37), a multifunctional peptide, is expressed by ocular surface epithelia and has potent antibacterial and antiviral activity. Curr. Eye Res. 30(5), 385-394 (2005).

81. Alagarasu K, Patil PS, Shil P et al. In vitro effect of human cathelicidin antimicrobial peptide LL-37 on dengue virus type 2. Peptides 92 , 23-30 (2017).

82. Sousa FH, Casanova V, Findlay F et al. Cathelicidins display conserved direct antiviral activity towards rhinovirus. Peptides 95, 76-83 (2017).

83. Currie SM, Findlay EG, Mchugh BJ et al. The human cathelicidin LL-37 has antiviral activity against respiratory syncytial virus. PLoS ONE 8(8), e73659 (2013).

84. Currie SM, Gwyer Findlay E, Mcfarlane AJ et al. Cathelicidins have direct antiviral activity against respiratory syncytial virus in vitro and protective function in vivo in mice and humans. J. Immunol. 196(6), 2699-2710 (2016).

85. Tripathi S, Tecle T, Verma A, Crouch E, White M, Hartshorn KL. The human cathelicidin LL-37 inhibits influenza A viruses through a mechanism distinct from that of surfactant protein D or defensins. J. Gen. Virol. 94(Pt 1), 40-49 (2013).

86. Schogler A, Muster RJ, Kieninger E et al. Vitamin D represses rhinovirus replication in cystic fibrosis cells by inducing LL-37. Eur. Respir. J. 47(2), 520-530 (2015).

87. Telcian AG, Zdrenghea MT, Edwards MR et al. Vitamin D increases the antiviral activity of bronchial epithelial cells in vitro. Antiviral Res. 137, 93-101 (2017).

88. Barlow PG, Beaumont PE, Cosseau C et al. The human cathelicidin LL-37 preferentially promotes apoptosis of infected airway epithelium. Am. J. Respir. Cell Mol. Biol. 43(6), 692-702 (2010).

89. Kahlenberg JM, Kaplan MJ. Little peptide, big effects: the role of LL-37 in inflammation and autoimmune disease. J. Immunol. 191(10), 4895-4901 (2013).

90. Monlezun DJ, Bittner EA, Christopher KB, Camargo CA, Quraishi SA. Vitamin D status and acute respiratory infection: cross sectional results from the United States National Health and Nutrition Examination Survey, 2001-2006. Nutrients 7(3), 1933-1944 (2015).

91. Martineau AR, Jolliffe DA, Hooper RL et al. Vitamin D supplementation to prevent acute respiratory tract infections: systematic review and meta-analysis of individual participant data. BMJ 356, i6583 (2017).

92. Fritsche J, Mondal K, Ehrnsperger A, Andreesen R, Kreutz M. Regulation of 25-hydroxyvitamin D3-1 alpha-hydroxylase and production of 1 alpha,25-dihydroxyvitamin D3 by human dendritic cells. Blood 102(9), 3314-3316 (2003).

93. Hansdottir S, Monick MM, Hinde SL, Lovan N, Look DC, Hunninghake GW. Respiratory epithelial cells convert inactive vitamin D to its active form: potential effects on host defense. J. Immunol. 181(10), 7090-7099 (2008).

94. Liu PT, Stenger S, Li H et al. Toll-like receptor triggering of a vitamin D-mediated human antimicrobial response. Science 311(5768), 1770-1773 (2006).

95. Greiller CL, Martineau AR. Modulation of the immune response to respiratory viruses by vitamin D. Nutrients 7(6), 4240-4270 (2015).

96. Brockman-Schneider RA, Pickles RJ, Gern JE. Effects of vitamin D on airway epithelial cell morphology and rhinovirus replication. PLoS ONE 9(1), e86755 (2014).

97. Thijs W, Janssen K, Van Schadewijk AM et al. Nasal levels of antimicrobial peptides in allergic asthma patients and healthy controls: differences and effect of a short 1,25(OH)2 vitamin D3 treatment. PLoS ONE 10(11), e0140986 (2015).

98. Schrumpf JA, Amatngalim GD, Veldkamp JB et al. Proinflammatory cytokines impair vitamin D-induced host defense in cultured airway epithelial cells. Am. J. Respir. Cell Mol. Biol. 56(6), 749-761 (2017).

99. Isaacs A, Lindenmann J. Virus interference. I. The interferon. Proc. R. Soc. Lond. B Biol. Sci. 147(927), 258-267 (1957).

100. Taylor J. Inhibition of interferon action by actinomycin. Biochem. Biophys. Res. Commun. 14, 447-451 (1964).

101. Marcus PI, Salb JM. Molecular basis of interferon action: inhibition of viral RNA translation. Virology 30(3), 502-516 (1966).

102. Nan Y, Nan G, Zhang YJ. Interferon induction by RNA viruses and antagonism by viral pathogens. Viruses 6(12), 4999-5027 (2014).

103. Loo YM, Fornek J, Crochet N et al. Distinct RIG-I and MDA5 signaling by RNA viruses in innate immunity. J. Virol. 82(1), 335-345 (2008).

104. Bowie AG, Unterholzner L. Viral evasion and subversion of pattern-recognition receptor signalling. Nat. Rev. Immunol. 8(12), 911-922 (2008).

105. Wang Q, Nagarkar DR, Bowman ER et al. Role of double-stranded RNA pattern recognition receptors in rhinovirus-induced airway epithelial cell responses. J. Immunol. 183(11), 6989-6997 (2009).

106. Triantafilou K, Vakakis E, Richer EA, Evans GL, Villiers JP, Triantafilou M. Human rhinovirus recognition in non-immune cells is mediated by Toll-like receptors and MDA-5, which trigger a synergetic pro-inflammatory immune response. Virulence 2(1), 22-29 (2011).

107. Lin T, Zhou W, Sacks SH. The role of complement and Toll-like receptors in organ transplantation. Transpl. Int. 20(6), 481-489 (2007). 
108. Guillot L, Le Goffic R, Bloch S et al. Involvement of toll-like receptor 3 in the immune response of lung epithelial cells to double-stranded RNA and influenza A virus. J. Biol. Chem. 280(7), 5571-5580 (2005).

109. Slater L, Bartlett NW, Haas JJ et al. Co-ordinated role of TLR3, RIG-I and MDA5 in the innate response to rhinovirus in bronchial epithelium. PLoS Pathog. 6(11), e1001178 (2010).

110. Abe $\mathrm{Y}$, Fujii $\mathrm{K}$, Nagata $\mathrm{N}$ et al. The toll-like receptor 3-mediated antiviral response is important for protection against poliovirus infection in poliovirus receptor transgenic mice. J. Virol. 86(1), 185-194 (2012).

111. Richer MJ, Lavallee DJ, Shanina I, Horwitz MS. Toll-like receptor 3 signaling on macrophages is required for survival following coxsackievirus B4 infection. PLoS ONE 4(1), e4127 (2009).

112. Lamborn IT, Jing H, Zhang Y et al. Recurrent rhinovirus infections in a child with inherited MDA5 deficiency. J. Exp. Med. 214(7), 1949-1972 (2017).

113. Becker TM, Durrani SR, Bochkov YA, Devries MK, Rajamanickam V, Jackson DJ. Effect of exogenous interferons on rhinovirus replication and airway inflammatory responses. Ann. Allergy Asthma Immunol. 111(5), 397-401 (2013).

114. Wark PA, Johnston SL, Bucchieri F et al. Asthmatic bronchial epithelial cells have a deficient innate immune response to infection with rhinovirus. J. Exp. Med. 201(6), 937-947 (2005).

115. Cakebread JA, Xu Y, Grainge C et al. Exogenous IFN-beta has antiviral and anti-inflammatory properties in primary bronchial epithelial cells from asthmatic subjects exposed to rhinovirus. J. Allergy Clin. Immunol. 127(5), 1148-1154 (2011).

116. Gaajetaan GR, Geelen TH, Vernooy JH et al. Interferon-beta induces a long-lasting antiviral state in human respiratory epithelial cells. J. Infect. 66(2), 163-169 (2013).

117. Gulraiz F, Bellinghausen C, Dentener MA et al. Efficacy of IFN-lambda1 to protect human airway epithelial cells against human rhinovirus 1B infection. PLoS ONE 9(4), e95134 (2014).

118. Field AK, Tytell AA, Lampson GP, Hilleman MR. Inducers of interferon and host resistance. II. Multistranded synthetic polynucleotide complexes. Proc. Natl Acad. Sci. USA 58(3), 1004-1010 (1967).

119. Hilleman MR. Prospects for the use of double-stranded ribonucleic acid (poly I:C) inducers in man. J. Infect. Dis. 121(2), 196-211 (1970).

120. Field AK, Tytell AA, Piperno E, Lampson GP, Nemes MM, Hilleman MR. Poly I:C, an inducer of interferon and interference against virus infections. Medicine (Baltimore) 51(3), 169-174 (1972).

121. Hill DA, Baron S, Perkins JC et al. Evaluation of an interferon inducer in viral respiratory disease. JAMA 219(9), 1179-1184 (1972).

122. Matsumoto M, Seya T. TLR3: interferon induction by double-stranded RNA including poly(I:C). Adv. Drug Deliv. Rev. 60(7), 805-812 (2008).

123. Kato H, Takeuchi O, Mikamo-Satoh $\mathrm{E}$ et al. Length-dependent recognition of double-stranded ribonucleic acids by retinoic acid-inducible gene-I and melanoma differentiation-associated gene 5. J. Exp. Med. 205(7), 1601-1610 (2008).

124. Wong JP, Saravolac EG, Sabuda D, Levy HB, Kende M. Prophylactic and therapeutic efficacies of poly(IC.LC) against respiratory influenza A virus infection in mice. Antimicrob. Agents Chemother. 39(11), 2574-2576 (1995).

125. Kende M. Prophylactic and therapeutic efficacy of poly(I,C)-LC against Rift Valley fever virus infection in mice. J. Biol. Response Mod. 4(5), 503-511 (1985).

126. Baer GM, Shaddock JH, Moore SA, Yager PA, Baron SS, Levy HB. Successful prophylaxis against rabies in mice and Rhesus monkeys: the interferon system and vaccine. J. Infect. Dis. 136(2), 286-291 (1977).

127. Zhao J, Zhao J, Van Rooijen N, Perlman S. Evasion by stealth: inefficient immune activation underlies poor T cell response and severe disease in SARS-CoV-infected mice. PLoS Pathog. 5(10), e1000636 (2009).

128. Guerrero-Plata A, Baron S, Poast JS, Adegboyega PA, Casola A, Garofalo RP. Activity and regulation of alpha interferon in respiratory syncytial virus and human metapneumovirus experimental infections. J. Virol. 79(16), 10190-10199 (2005).

129. Wong JP, Christopher ME, Viswanathan S et al. Activation of toll-like receptor signaling pathway for protection against influenza virus infection. Vaccine 27(25-26), 3481-3483 (2009).

130. Lau YF, Tang LH, Ooi EE. A TLR3 ligand that exhibits potent inhibition of influenza virus replication and has strong adjuvant activity has the potential for dual applications in an influenza pandemic. Vaccine 27(9), 1354-1364 (2009).

131. Antonelli LR, Gigliotti Rothfuchs A, Goncalves R et al. Intranasal Poly-IC treatment exacerbates tuberculosis in mice through the pulmonary recruitment of a pathogen-permissive monocyte/macrophage population. J. Clin. Invest. 120(5), 1674-1682 (2010).

132. Tian X, Xu F, Lung WY et al. Poly I:C enhances susceptibility to secondary pulmonary infections by gram-positive bacteria. PLoS ONE 7(9), e41879 (2012).

133. Spickler C, Lippens J, Laberge MK et al. Phosphatidylinositol 4-kinase III beta is essential for replication of human rhinovirus and its inhibition causes a lethal phenotype in vivo. Antimicrob. Agents Chemother. 57(7), 3358-3368 (2013).

134. Arita M, Kojima H, Nagano T, Okabe T, Wakita T, Shimizu H. Oxysterol-binding protein family I is the target of minor enviroxime-like compounds. J. Virol. 87(8), 4252-4260 (2013). 
135. Roulin PS, Lotzerich M, Torta F et al. Rhinovirus uses a phosphatidylinositol 4-phosphate/cholesterol counter-current for the formation of replication compartments at the ER-Golgi interface. Cell Host Microbe 16(5), 677-690 (2014).

136. Decor A, Grand-Maitre C, Hucke O et al. Design, synthesis and biological evaluation of novel aminothiazoles as antiviral compounds acting against human rhinovirus. Bioorg. Med. Chem. Lett. 23(13), 3841-3847 (2013).

137. Albulescu L, Bigay J, Biswas B et al. Uncovering oxysterol-binding protein (OSBP) as a target of the anti-enteroviral compound TTP-8307. Antiviral Res. 140, 37-44 (2017).

138. Guedan A, Swieboda D, Charles M et al. Investigation of the role of protein kinase D in human rhinovirus replication. J. Virol. 91(9), pii:e00217-17 (2017).

139. Staring J, Von Castelmur E, Blomen VA et al. PLA2G16 represents a switch between entry and clearance of Picornaviridae. Nature 541(7637), 412-416 (2017).

140. MousnierA, Bell AS, Swieboda DPFragment-derivedinhibitors of human N-myristoyltransferase block capsid assembly andreplication of the common cold virus. Nat. Chem. doi:10.1038/s41557-018-0039-2 (2018) (Epub ahead of print).

141. Jacobs SE, Lamson DM, St George K, Walsh TJ. Human rhinoviruses. Clin. Microbiol. Rev. 26(1), 135-162 (2013).

142. Smith TJ, Chase ES, Schmidt TJ, Olson NH, Baker TS. Neutralizing antibody to human rhinovirus 14 penetrates the receptor-binding canyon. Nature 383(6598), 350-354 (1996).

143. Che Z, Olson NH, Leippe D et al. Antibody-mediated neutralization of human rhinovirus 14 explored by means of cryoelectron microscopy and X-ray crystallography of virus-Fab complexes. J. Virol. 72(6), 4610-4622 (1998).

144. Dong Y, Liu Y, Jiang W, Smith TJ, Xu Z, Rossmann MG. Antibody-induced uncoating of human rhinovirus B14. Proc. Natl Acad. Sci. USA 114(30), 8017-8022 (2017).

145. Katpally U, Fu TM, Freed DC, Casimiro DR, Smith TJ. Antibodies to the buried N terminus of rhinovirus VP4 exhibit cross-serotypic neutralization. J. Virol. 83(14), 7040-7048 (2009).

146. Panjwani A, Asfor AS, Tuthill TJ. The conserved N-terminus of human rhinovirus capsid protein VP4 contains membrane pore-forming activity and is a target for neutralizing antibodies. J. Gen. Virol. 97(12), 3238-3242 (2016).

147. Traub S, Nikonova A, Carruthers A et al. An anti-human ICAM-1 antibody inhibits rhinovirus-induced exacerbations of lung inflammation. PLoS Pathog. 9(8), e1003520 (2013).

148. Salazar G, Zhang N, Fu TM, An Z. Antibody therapies for the prevention and treatment of viral infections. NPJ Vaccines 2, 19 (2017).

149. Cheung NN, Lai KK, Dai J et al. Broad-spectrum inhibition of common respiratory RNA viruses by a pyrimidine synthesis inhibitor with involvement of the host antiviral response. J. Gen. Virol. 98(5), 946-954 (2017). 